\title{
How is value created? - Extending the value concept in the Swedish context
}

\author{
Solveig Wikström ${ }^{\mathrm{a}}$, Patrick L'Espoir Decosta ${ }^{\mathrm{b}, *}$ \\ a Stockholm University School of Business, SE- 10691 Stockholm, Sweden \\ b Research School of Management, Australian National University, Crisp Building, 26 Kingsley Street, Acton ACT 2601, Canberra, Australia
}

\begin{abstract}
A B S T R A C T
This inductive study elaborates on the value concept and unpacks the process of how value is created in the Swedish food industry by combining the theoretical tool of goal hierarchy with the methods of network analysis. Through real world insights, on how consumers and retail firms act and coordinate their activities to fulfill their roles in consumer value creation, this study proposes a differing perspective that extends the value-in-use concept by identifying four sequential consumer activities. They are (i) reflections about what is important (value) in the specific consumption situation (the focal goal), (ii) the starting point of value creation (selection and application of means), (iii) the process involved in providing and enjoying holistic solutions, and (iv) ultimately its contribution to life fulfillment in the sense that value creation is meaningful. Thus, consumers create value by setting clear differential hierarchical goals that include the identification of resources and consumers' own capacity before choosing the products and using them. The network analyses also reveal an additional space for supporting value creation: firm to firm interactions which add more resources to providers' support of consumer value creation. The paper provides new real world insights on how consumers and firms act to fulfill their roles in consumer value creation. This knowledge helps retailers to better identify and manage value creation tools to support their customers in value creation.
\end{abstract}

\section{Introduction}

Consumer value is a central topic in current management and marketing discourse and has been made more relevant through important current research contributions that highlight different aspects of the value concept. Contributions include those of Vargo and Lusch (2004, 2008) and Grönroos $(2008,2011)$ within the service dominant logic and more recently by Heinonen et al., (2010, 2013) and Boysen Anker et al. (2015) within a customer dominant logic, and by Andreu et al. (2010) from a management perspective. One commonality throughout these contributions is the lack of a clear depiction of the process involved in and empirical evidence of value creation (Grönroos and Voima, 2013), thus confirming Ind and Coates' (2013) claim that value creation is still an emerging concept. Intertwined with this lacuna are firms' efforts to ensure support for consumers' value creation, either individually or collectively, in practice (Payne et al., 2008) and in theory (Prahalad and Ramaswamy, 2004). Despite these important conceptual contributions, the entire value creation process has not been studied in depth. Limited theoretical knowledge and almost no practical examples exist, aside from the furniture sector illustration by Andreu et al. (2010), about how consumers act to create value, which is commonly taken in the literature to mean "value-in-use" (Vargo and Lusch,
2004, 2008; Grönroos, 2011; Grönroos and Voima, 2013). Another empirical contribution is Mencarelli and Lombart's study (2017) demonstrating the payoff of creating consumer value by stating that perceived value is a more accurate predictor of attitudinal and behavioral loyalty than is satisfaction.

This paper posits that the concepts and processes suggested so far have merely adopted a theoretical conceptual perspective to consumer value creation (Grönroos, 2008), rather than identifying and describing the mechanisms in the process. For example, Payne et al. (2008) map, at the meso level, how consumers engage in value creation through processes and practices but do not identify the inherent steps in value creation "engagement" itself. This paper is a response to the call by Payne et al., (2008) for more research on frameworks to help manage value creation and to empirically inquire at the micro level about the interactions and exchanges among the resources and practices in value creation processes (Andreu et al., 2010). Thus, the purpose of this study is to theoretically and holistically elaborate on the value concept by unpacking the process by which value is created. This requires grounding the entire value creation process in empirical data, from the very thoughts and reflections on consumption of a particular product area to product selection and use. In other words, this study previses the frameworks of Grönroos and Voima (2013) and of Payne et al. (2008)

\footnotetext{
* Corresponding author.

E-mail addresses: SW@sbs.su.se (S. Wikström), Patrick.lespoirdecosta@anu.edu.au (P. L'Espoir Decosta).
} 
by using goal hierarchy as a theoretical lens to uncover firm- and consumer-led activities that create value in the network setting in the Swedish consumer goods area. These activities, we argue, are in fact the mechanisms by which value creation processes, as identified in the conceptual framework of value co-creation by Payne et al. (2008), are revealed. We embrace the existing concepts that consumers create value (Grönroos and Voima, 2013) and that firms are the facilitators of consumers' value creation (Vargo and Lusch, 2004, 2008). We also assume that consumer value creation is always dependent on interactions and exchanges between firms and consumers, be they direct or indirect. We employ Swedish consumer goods consumption as the empirical context and conduit to explicate and detail the concept of value throughout the different stages of its creation and use in a consumer goal setting and goal hierarchy approach (Bagozzi and Dholakia, 1999). Such a goaloriented approach is useful, as it includes both the process of consumer value creation and its outcome. It is appropriate because goals and value are compatible, in that they signal the factors, notions and issues of importance to consumers (Bagozzi and Dholakia, 1999). Furthermore, this approach helps capture both firm- and consumer-led activities by which the process of consumer value creation is revealed.

To achieve its main goal, this paper addresses the primary question of "How is value created?" by posing the following sub-questions:

- What constitutes value in a given consumption situation?

- How do singular components of value contribute to the experience of value in a specific consumption area?

- What are the contributions of the different actors in value creation? and

- How can consumer value be attained?

\section{Theoretical context}

\subsection{The concepts of value and value-co-creation}

The concept of value still lacks a consistent definition (Gallarza et al., 2011; Boksberger and Melsen, 2011)) as it is difficult to define and measure (Grönroos, 2008). However, a generic and useful definition from value theory refers to the degree of goodness derived from consumption (Gordon, 1964; Lamont, 1955). Thus, consumers' achievement of "goodness" could be considered equivalent to the capturing of consumer value (Ravald and Grönroos, 1996). More precisely, Grönroos (2011, p.11) clarifies that "value creation cannot mean anything other than the customer's, or any other user's, experiential perception of the value-in-use that emerges from usage or possession of resources, or even from mental states." Within the service dominant logic, Vargo and Lusch (2004) convey the view of "potential" value from a product that also includes service elements. However, when juxtaposed with Grönroos' (2011) claim that producers in fact generate "potential" value that would only be "realized," and therefore "created," during consumer usage, then "potential" value is "created" at the moment a product is used. To that end, value-in-use has become the common understanding of what constitutes consumer value (Grönroos and Voima, 2013; Wikström, 1996). One ramification of this logic is that there is no certainty as to who actually leads value creation (Grönroos, 2011). A central theme in value discussions is where and by whom value is created. By illation, and in spite of the many definitions of value and value-in-use, little is known about how value is created (Vargo et al., 2008) and how different components of value contribute to value creation as previously researched by Woodruff (1997). The goal hierarchy approach applied in this study addresses the questions of what constitutes value in a given consumption situation and how this value can be attained.

Though Grönroos and Voima (2013) identified three different spheres (consumer, provider and joint) where value creation is pursued and argued that value-in-use is attained by direct and indirect interaction with firms, and that value creation is an ongoing process, there is no clear explanation nor empirical evidence of the process by which actors contribute to consumers' perceptions of value-in-use; i.e., how actors in the different spheres act to create value. Grönroos, p.282) (2011) laments this fact: "[...] we know very little about the process of value creation, when it starts, what it includes, when it ends." The discussion by Heinonen, p.109) et al. (2013) about how value is created inconclusively ideates that value "emerges through customers' behavioral and mental processes," without actually identifying the intricacies and explicating those processes. Similarly, in their integrative framework of value co-creation as applied to the furniture market in Spain, Andreu et al. (2010) clearly identified the value-creating facilitator role of suppliers, retailers and consumers, but never explicitly addressed the "how" question. Interestingly, though these authors incidentally highlighted the three value creating processes that rely on the cross-fertilization of knowledge, competences and practices, which could eventually facilitate the identification of the mechanisms involved in those processes, they never uncovered the mechanisms involved in value creation. As such, based on existing literature, the three spheres identified by Grönroos and Voima (2013) represent so far the most advanced conceptualization of how consumer value is created and who creates it. Interestingly, the empirical studies by Andreu et al. (2010), Payne et al. (2008) implicitly acknowledge the significance of value as outcome and goal (Grönroos, 2008) such that value acts as a compass that assists customers in their consumption decisions (Edvardsson et al., 2006). Subsequently, to uncover in detail the mechanisms in the value creation process, we need to first critically appraise the significance of goals and goal settings in the process, and second, to critically argue for the need to integrate the network approach in the study, given the roles played by social and economic actors as resource integrators (Vargo and Lusch, 2008) in the three spheres.

\subsection{Significance of goals in value creation}

The literature provides an additional perspective where the concept of value is equated with the concept of goals and goal setting (Gutman, 1997; Sirdeshmukh et al., 2002) such that goals become a prerequisite to value creation. Indeed, both Gutman (1997) and Bagozzi and Dholakia (1999) explicitly refer to value as goal desirability. Value as such entails what Holbrook (2006) calls "subjective hierarchical preferences," (p.715), which consequently create a hierarchical organization of consumers' goals and goal-setting behavior (Gutman, 1997). This is a natural means of investigating the concepts of consumer value and the process of value creation.

Perhaps the most well-known motivational theories, Maslow's (1943) hierarchy of needs, further developed by Herzberg, Mausner and Snyderman (1959), is also related to goals. However, the emphasis in Maslow's (1943) hierarchy is ultimately on strictly arranged interdependent levels of basic human needs that act as motivators for behavior. In this study, we view behavior as goal-directed and composed of a specific goal that is hierarchically arranged according to its degree of abstraction, starting with the means to attain the goal at the peak of the hierarchy, which signifies why consumers want to achieve that for which they strive. In that sense, following Pieters et al. (1995) and Bagozzi and Dholakia (1999, p.20), consumer goal-directed behavior here includes the process of goal setting and goal pursuit.

The procedure starts with the basic question: "What are my desired goals?" Given a particular goal of, for example, acquiring good food, the next issue in goal setting becomes: "How can I achieve my goals?" To address this question, goals are perceived as interrelated and organized in a hierarchy (Gutman, 1997). The focal goals located at the centre of the goal hierarchy answer the question: "What am I striving for?" The subordinate goals, located at the bottom of the hierarchy, constitute the means of achieving the focal goals and consist of sub-goals that must be attained in order to reach higher-level goals (Pieters et al., 1995). At the apex of the hierarchy are the superordinate goals, which clarify the overarching reasons behind consumers' desire to achieve that for which 
they strive (the focal goal).

The questions posed to consumers about certain types of consumption serve to provide a detailed picture of the goal hierarchy. However, because focal goals are instrumental (Sirdeshmukh et al., 2002), they are what Gutman (1997) calls action goals. We posit that higher-level goals can only be achieved if lower-level goals are satisfied. In that sense, by focusing primarily on the achievement of focal goals, our study supports Gutman's argument that goals as motivators of behavior (Pieters et al., 1995) facilitate the depiction of the process involved (vertically upward throughout the hierarchy) in value creation, which ultimately rests at the superordinate level (the reason for value creation). However, given that focal goals are instrumental, they have an ontological affinity with value creation as process. Our emphasis on them is therefore theoretically motivated. Given that value can be derived at all levels in the hierarchy, applying such a goal hierarchy approach theoretically broadens the concept of consumers' value creation.

\subsection{The network approach to value creation}

This paper posits that, in their support of consumer value creation, firms (suppliers and retailers) similarly follow a goal hierarchy approach. Firms' strategies related to product and assortment development represent their focal goal, and their operative activities are the subordinate goals; i.e., the means by which they achieve their focal goal. In this case, a well-functioning network presupposes a fit between the goals of firms and consumers in that they have to strive in the same direction (Sarker et al., 2006); i.e., to promote and assist in consumer value creation, in this case in food consumption.

Of significance here is the existence of a linkage between the value creating activities of the three actor groups, which reinforces the interdependent relationships in their accomplishments. The network approach, which is defined as a group of actors (firms and/or consumers) that interact (cooperate) in pursuing activities that promote value creation in the network (Grönroos, 2011) enables the exploration of such relationships between interdependent actors in the market (Gummesson, 2002). However, extant theories are not explicit about whether such interaction is direct or indirect. Instead, it is emphasized that the glue binding together the entire network is "the elaborate pattern of interdependence and reciprocity" (Achrol, 1997, p.61), that coordination and integration among actor members promote efficiency and value creation (Lusch et al., 2010; Payne et al., 2008), and that a "grey" zone between direct and indirect interaction may actually blur the lines between spheres (Grönroos and Voima, 2013: p.143) as the joint sphere in fact represents an area of uncertainty. In this zone, interactions between firms and consumers may be difficult to structure in terms of being direct and/or indirect. In a supermarket, for instance, indirect interaction dominates, but there are also some clerks on the floor whom customers can directly consult. Additionally, a network allows for the simultaneous pursuit of individual and network goals by its different constituencies (Latour, 2005). This study proposes a conceptual model of value creation based on network theory to structure data acquisition and analyze consumer value creation in the Swedish food market network context (see Fig. 1).

The model depicts the goal-oriented activities of the three main actors in the food network: suppliers, retailers and consumers. To understand the network, the actors' interaction and coordination mechanisms must be identified. In this case, the arrows in the figure pointing in both directions illustrate how coordination activities are inter-linked to fulfill the network goal, which is defined as consumer value creation. The traditional role of the supplier is to support consumer value creation by offering products and services to be used by consumers as input in the value creation process (indirect interaction). The role of the distributor/retailer is to act as a link between production and consumption by offering a range of options from which consumers can choose according to their preferences (often from a merged dialogue). Suppliers and retailers, however, are significant for another reason: their cooperation creates opportunities for additional support to consumer value creation (Esper et al., 2010) and for new types of offerings. The coordination of their activities uncovers offerings built on resources from both producers and retailers. Such offerings can be of a holistic nature and more complex than offerings initiated by interactions between consumers and retailers and between consumers and producers. As in our case, such multidimensional offerings are in line with consumers' focal goals (see Fig. 2). Hence, this study identifies a new source for support of consumer value creation that goes beyond Grönroos and Voima (2013) by effectively making the case through empirical evidence in the food industry for a holistic approach that looks into the "grey zone" (Grönroos and Voima, 2013, p. 143), not only between direct and indirect interactions but across the three spheres. This study thus questions the "logics" approach (to value creation) of merely "include[ing]" (Grönroos and Voima, 2013, p.135) actions of both providers and customers. By bringing the firms and consumers together through an integration of the goal hierarchy and network approaches, we identify a fourth space for value creation, beyond the established view of how value is created. This requires a reassessment of relationships and interactions in the network that have heretofore been taken for granted. To that effect and to explore the different intricacies and constellations of contributors in value creation, the question related to the process by which value is created becomes: "How is value created?"

\section{Study method}

To capture the process by which consumers create value through a network-integrated hierarchy of goals, this paper employs a qualitative research approach, deemed useful to obtain descriptive information about the complex network relationships in the Swedish food industry. This industry has a significant influence on health and well-being and thus has encountered considerable consumer criticism (Grunert and Wills, 2007; Hohl and Gaskell, 2008). In addition, the food industry in Sweden is highly concentrated. In the retail market, three firms represent $90 \%$ of sales, with one enjoying a $50 \%$ market share. This high degree of market concentration complicates the relationships between production and retail firms and is as such noteworthy, not only at the level of agency but also in identifying the characteristics involved in the processes and their likely outcomes within the network. As in other fastmoving consumer goods (FMCG) industries, large retailers have increased their market share in recent decades, noticeably shifting power toward retailers (Swedish Competition Authority, 2011). Moreover, a relatively small number of large brands, together with private label brands, dominate the supply side (Swedish Competition Authority, 2011). These trends and influencing factors are also visible in several other countries. The empirical case of the Swedish food industry involves three interacting players anonymized here:

(i) a retail unit that controls $20 \%$ of the retail market. This unit consists of two retail chains with a common purchasing organization. Data were collected from seven interviewees in executive and senior management positions;

(ii) four of the retail unit's most important suppliers, represented by 23 interviewees with positions at both the executive and senior management levels encompassing the departments of sales and marketing, product development and market intelligence; and

(iii) a panel of 35 households that are customers of the retail chains. ${ }^{1}$ The household panel is composed in equal parts of families with young children, families with teenagers and "empty nest" families. A purposive sample was used to recruit representatives of these families outside of stores in different areas of Stockholm (see Table 1). Half of the sample was recruited from the firm's lower-

\footnotetext{
${ }^{1}$ [Information retained for blind review process].
} 


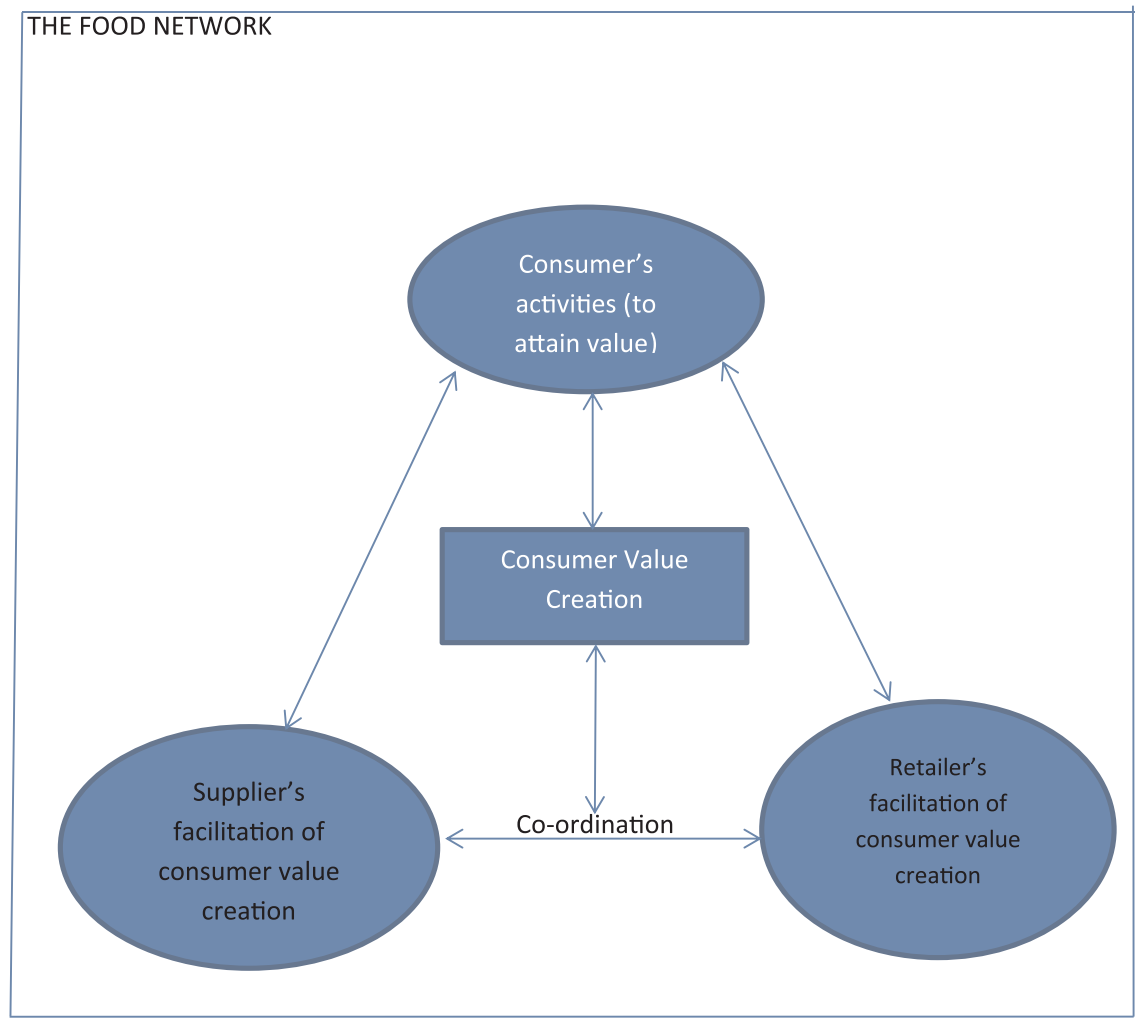

Super-

ordinate

goals

(Why?)
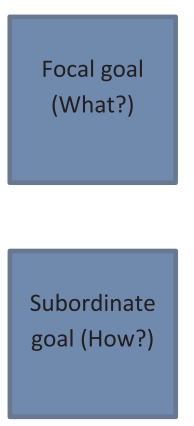

Sub-

subordinate

goals

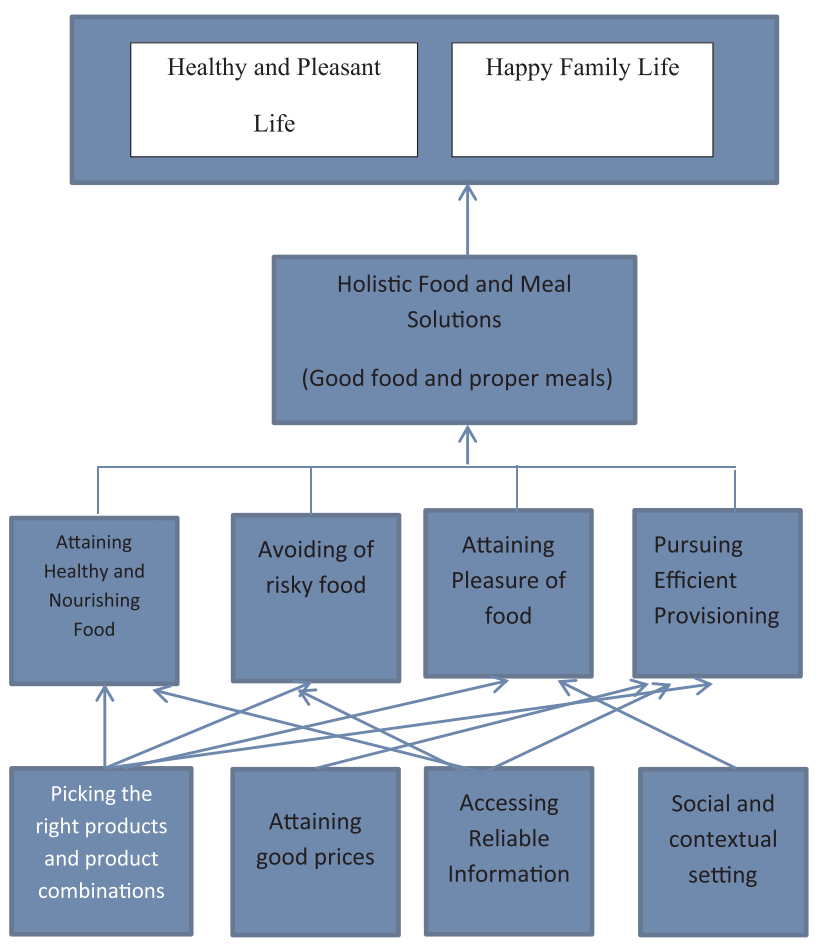

Fig. 1. Relationships and activities of the network actors' creating and facilitating of consumer value creation.

Fig. 2. Consumer's goal hierarchy.

experiences with food acquisition, consumption and meal arrange-

priced retail chain and the other half consists of families that frequent the firm's higher-priced retail chains.

A two-pronged data collection with consumers and firms (suppliers and retailers) was performed in several rounds between 2008 and 2009. First, we conducted in-depth probes $^{2}$ with consumers about their

\footnotetext{
${ }^{2}$ These included in-depth questioning of respondents so to gather thick descriptive
}

ments. The inquiry focused on consumers' goals: what is important to them in food consumption and meal preparation; how they act to attain their goals, and what strategies they apply. We then discussed outcomes

(footnote continued)

answers to mostly "why" and "how" questions related to the goals and motivations behind their purchasing behavior and choices. 
Table 1

List of interviewees (Consumers)

\begin{tabular}{|c|c|}
\hline Consumers & \\
\hline CYM $1^{\text {a }}$ & Åsa, Anders with 1baby Tom, 2, \\
\hline CYM 2\# & Jonas, Annica with 2 sons, Melker 3 and baby son Love, 1 , \\
\hline CYM 3 \# & Caroline, Luis with 2 daughters Ashima, 5, and Marina, 1 \\
\hline CYM 4 \# & Per and Caroline with 2 daughters, Julia 3.5 and Stina 1.5 \\
\hline CYM 5 \# & Helena and Lotta with 2 sons, Sixten 3 and Kalle 2 \\
\hline CYM $6^{\mathrm{b}}$ & Erik, Anna with 1 son Viktor 3 , \\
\hline CYM 7 \# & Theresa,Tommy and their son Kim \\
\hline CYM 8\# & Petra, Tommy and their sons Erik and Adrian \\
\hline CYM 9\# & Niklas and Annika with their 2 children Melker (3) and Sussie (1) \\
\hline CYM 10 \# & Laila, Don and their baby boy \\
\hline CEN 1 \# & Eva and John, retired couple in an empty nest \\
\hline CFT 1 \# & Petra and Göran with 2 children, Marcus, 15 and Lina 13, \\
\hline CFT 2\# & $\begin{array}{l}\text { Birgitta and Leif with } 5 \text { children, aged from } 5 \text { up to the early } \\
\text { teenage years }\end{array}$ \\
\hline CFT $3 \#$ & Mats and Åsa with 2 children, Adam 16 and Elin 10 \\
\hline CFT 4\# & $\begin{array}{l}\text { Susanne and Lasse with } 3 \text { children, Viktor 21, Bella } 18 \text { and Susie, } \\
13\end{array}$ \\
\hline CFT $5 \#$ & Eva and Mats with 2 sons, Tobias, 20 and David, 18 \\
\hline CFT 6\# & $\begin{array}{l}\text { Laila and Robert, with } 3 \text { children, Carl, } 23 \text { and Erik, } 21 \text { and } \\
\text { Liselotte, } 18\end{array}$ \\
\hline CFT 7 \# & $\begin{array}{l}\text { Anna and her } 2 \text { teenage boys Tom and Jacob and her daughter } \\
\text { Harriette, } 5\end{array}$ \\
\hline
\end{tabular}

a CYM - family with young children.
${ }^{\text {b }}$ CFT - family with teenage children.

regarding the extent to which consumers could attain their goals, and what their primary obstacles were. Each interview was carried out in Swedish and lasted a minimum of one hour. Thereafter, participative shopping ${ }^{3}$ helped determine the respondents' shopping behaviors (what they were actually doing while shopping). Participative shopping also provided opportunities to address ambiguities in the informants' earlier responses. Finally, purchase receipts were analyzed to determine consistency between what consumers said and what they actually did. Indeed, information from the informants was obtained in several rounds, which allowed for collation and therefore increased the credibility of data on how consumers perceive value.

We collected data from the firms through semi-structured interviews with senior and executive managers that focused on firms' interactions with consumers and with each other in their efforts to support consumer value. The questions we posed covered two major issues:

- Marketing activities, consumer information acquisition, and the dissemination of consumer information within firms.

- The types of cooperation and issues involved in interactions between retailers and providers, such as openness of the relations, information sharing, product development, private brands, and conflicting goals.

Interviews with the firms' representatives were complemented with (i) notes gathered by the researchers during seven full-day workshops held over three years on the implementation of consumer orientation principles and the ensuing need for communication among the firms, and (ii) internal documents that include consumer research reports from the firms. The goal approach ensured that the goal map for the different sets of players converged, despite their different origins.

\section{Analysis and findings}

A within-case analysis was carried out at the two levels (Yin, 2003) of consumers and firms, with a focus on how they interact in the

\footnotetext{
${ }^{3}$ This activity included interviewers "shadowing" the respondents while they were shopping to collect information about their shopping behavior, the questions, hesitations, and reasoning behind their shopping behavior and choices.
}

creation of consumer value in an industry that is naturally linked with the consumption of food, including meal arrangements. A final level of analysis was conducted through the juxtaposition of the findings for each group of actors (consumers and firms) to facilitate comparison of their activities to ultimately demonstrate how these two groups relate in the network and together help co-create value for consumers. In that sense, the within-case analysis and the later juxtaposition of findings for both consumers and firms are integral to the analytical triangulation employed here. As qualitative analysis was ongoing, complex and arduous, one researcher who acted as a sounding board crosschecked the findings from the within-case analysis (Giovanardi et al., 2014). The constant revisiting of the emerging theory with concrete evidence and examples from the case resonates with the theoretical sampling strategy of the grounded approach (Strauss and Corbin, 1998). This included requiring the views of firms' representatives to be periodically verified during the two years of the study. Such an emic approach reinforced the trustworthiness of the findings (Perry, 1998).

The interviews with consumers and firms were transcribed and reduced through the coding process following Glaser (2011) to identify emerging patterns of reactions. Themes of explanation were identified by categorizing passages of text in the data set representing more general phenomena at each level of the goal hierarchy. These themes were grouped into more general and higher conceptual classes. Thus, the units of data represent empirical indicators of more general constructs of interest. When engaged with the substantive areas of explanation from Bagozzi and Dholakia's (1999) three-level goal hierarchy, this iterative process of coding and comparison allowed the focal goal of consumers and firms to surface.

\section{The consumer level}

Through the iterative process of coding and comparison of the consumer interviews, the focal goal of "holistic food and meal solutions" emerged. The focal goal represents what consumers strive for in their food and meal consumption. This includes four themes explaining how consumers act to attain their focal goal that consist of a combination of several lower-level subordinate goals (means) (see Fig. 2).

The themes explain how and why consumers acquire good food and prepare proper meals. They do so by (i) acquiring healthy and nourishing food for physical well-being, (ii) attaining product combinations for an optimal shopping bag, (iii) focusing on prices of food to manage the family budget, and (iv) attaining sensory and social pleasure through food. The goal hierarchy thus facilitates concentration on the instrumentality of the focal goals. Following Rintamäki et al. (2007), value is considered multidimensional in terms of its functions, the emotions involved, and its economic significance. Finally, the overall combination of focal goals with the two levels of subordinate goals make it possible to attain the highest level of goals within the hierarchy; i.e., the superordinate goals of "healthy and pleasant life" and "happy family time." The latter relates to the why consumers go through these levels of experience to create multidimensional value through food consumption.

\subsection{Holistic food and meal solutions}

In their quest to reach the focal goal of holistic food and meal solutions, consumers do not initially interact directly with specific firms. Instead, of significance here is the consumer's early experience with available products and meal arrangements. This step in value creation shows that consumers forego the search for and choice of specific products that enable them to attain value-in-use. Accounts of consumers' activities demonstrate that to create value-in use, activities occur mainly without direct interaction with the firms' processes. Consumers generally rely on product displays and information on packages to locate what they want, except for products selected from delicatessen counters. Nonetheless, consumers use firms' offerings as input in creating value-in-use. The data helped identify seven primary 
strategies or means that consumers use to reach their focal goals. These strategies operate at both the subordinate level (to attain the focal goal) and at the sub-subordinate level, where they act as support to the subordinate goals (see Fig. 2).

\subsection{Acquiring healthy and nourishing food}

Unsurprisingly, the data revealed that nutritional and health attributes are a significant means for consumers to achieve physical wellbeing. This value dimension appears in different forms in consumers' stories. Health and "feeling good" are words and expressions typically used to refer to food-related value relating to physical and mental wellbeing.

The types of food that contribute to "feeling good" depend on the individual and the family. Nutrition, as part of health goals, stimulates depth of processing for families with children, as the latter's health is a vital superordinate goal for most parents who want their family to "buy organic, eat more vegetables and fruits and vegetarian food more often" (CYM 5). Families talking about healthy food refer to nutritious food "...that provides nutrients for the body," (CYM2) and to "good food...that is healthy and provides variety" (CYM 7) in support of a child's development. Furthermore, good food is often associated with "organic food that tastes better" (CYM3). Families acknowledge, however, that such an endeavor can be a burden on the family's budget and is subject to opportunity costs, as "organic food is also more expensive" (CYM 7).

To older consumers, new problems arise when they try to match appropriate food and eating with their health status: "When you get older, it is important to eat proper food, and for those of us with certain health problems, suitable food is a must. Because of diabetes and high blood pressure, we try to avoid sugar and fat and to cut down on salt" (CEN 1). The challenge is access to appropriate food, as "...with age comes a difficulty in reading the text on packages" (CEN1). Thus, they create demands that they expect will be satisfied by firms: "We think that the food industry could do much more for us" (CEN 1). As a growing part of the population, the elderly expect greater collaboration from firms in the form of better and more easily accessible information on consumption processes and healthy food. Moreover, food must meet other preconditions to be considered healthy. Food has to be safe and risky food has to be avoided.

Food ingredients perceived as potentially harmful to children are particularly significant: "... for those of us with young children, it is more important than before to serve healthy and nutritious food" (CYM 8). Facilitating the avoidance of "...processed food, as this type of food contains fat, with a low protein content, contains preservatives and flavor enhancers" (CYM2) is the search for more information from unbiased experts: "The ideal would be certified food and meal alternatives that stand for good food, food that meets all our important needs and wants" (CYM 9).

Such a situation makes assembling suitable "shopping bags" a daunting proposition. Therefore, the significance of the firms' input in terms of food-related information cannot be underestimated in the consumers' experience and suggests that at this level, value is co-created in the blurred (joint) area between consumers and firms.

\subsection{Best price}

"Best prices" are an important value dimension in acquiring provisions for families, as expressed in the following comments: "it is important to consider the price" (CFT2); "prices should be reasonable" (CFT4); "a low price influences my choice of food" (CEN1). The best price is particularly important for families with young children. As much as these families would ideally like to indulge in freshly made foods, however, they are constrained by the realities of limited time and financial resources: "we have to stick to processed food and ready-made meals," which "creates anxiety for us... [as] with our bigger family, money is tight. When we shop for food we now have to look at prices" (CYM 9). Striving for low prices can also be a motivation for consumers, as expressed by this retired couple: "Food is expensive, so we try to avoid buying at full price. We always check special offers. Buying at a low price gives us a feeling of being in control. Finding the best price gives a kick" (CEN 1). Hence, acquiring food at the best price is not only about a functional value dimension, but also an experiential and emotional one.

\subsection{Product combination}

The most important value-creating dimension is consumers' ability to select the right products and product combinations for food preparation and meal provision. However, several families reveal they have difficulties in choosing the right combinations given the many demands they put on food. To one family with two teenagers, more regulations "would help to distinguish between, for instance, price and environmental considerations and price and quality" (CYM 4). Similarly, a father with two teenagers laments, "the service in stores is poor. It is difficult to find a knowledgeable clerk on the floor. I wish there were an information desk where you could speak to someone with competence and authority" (CFT 3). Consumers invariably experience difficulties in achieving their objectives, which they attribute to limited access to reliable information both before visiting the store and in situ: "There is much discussion about organic food, but I don't know how it affects your health," (CFT6) and to resource and cognitive constraints that foster uncertainty: “... I don't trust what food producers and retailers actually say" (CFT 3). Uncertainty due to limited information and knowledge limits the competence of consumers as "operant resources" because both suppliers and retailers fail to specify and integrate resources that are necessary for a fruitful collaboration with consumers and that will allow consumers to apply their knowledge to make informed decisions (Lusch et al., 2007). Thus, to the father with two young children, because "...it is difficult to make decisions about food in order to guarantee good food for my family," uncertainty becomes a frequent source of stress, as he has ".... not found a working strategy for how to resolve the issues around food and meal choices" (CYM 9). Due to an abundance of products and freedom of choice, it is not just a matter of finding and selecting suitable individual products and services, but rather of choosing packages of food items that will reconcile the often contradictory demands on food. To Mats, the problem is "how to solve the many contradictory claims of my family members, including mine" (CFT 3). This explains why consumers typically complain about difficulties in "picking" the right products and product combinations. Together with the other subordinate goals, they support and justify the consumers' focal goal of holistic food and meal solutions. In that sense, the complexity justifies the conceptualization of consumers' focal goal in this study as "holistic solutions to food and meal arrangements." While food quality and price are not surprising value dimensions, as well as health and safety (Warde, 1997), product combinations add a novel value dimension to food and meal arrangements. This finding underpins our conclusion that consumers' focal goal in food and meal consumption is holistic solutions.

\subsection{Pleasure of food}

The potential for food to provide sensory pleasure is an important source of consumers' experiential value. Pleasure of food is not just about food but also relies on other underpinnings of social and contextual dimensions that are equally important. Food as a sensory experience and food consumption that provides explicit pleasure are primarily associated with weekend meals and cozy Friday night snacks that family members perceive as a special treat. Beyond the contexts within which foods are displayed, the atmosphere and companionship they foster are of utmost importance: "What I truly appreciate is having guests over (on the weekend) and preparing a good meal for them.... On these occasions, the whole experience, not just the food, becomes something to enjoy... and eating together is a happy social event" (CFT 7). The pleasure derived from food in these moments attains a different level of 
hedonic experience, combining social and hedonic value dimensions. This is in contrast to the "sort of necessary feeding" (CFT 7) by merely "providing everyday food... that you serve for health and nutritional reasons, as well as time and money constraints, during the week" (CFT 7).

Most families strive for social value in their everyday dinners as well and value the opportunity to eat together in a quiet and harmonious atmosphere, although this is often not realized. Indeed, the increasing tendency toward individualization in modern food consumption makes it tricky to ensure "a nice and quiet family dinner when we talk about the events of the day" (CFT 1). Harmony is an important dimension and facilitator of value creation that is related to the superordinate goal of a happy family life through food consumption. It combines social and sensory attributes in furtherance of the experiential value of pleasure of food. In modern families, "food at dinner time is an essential part ... and precious moment of our life" (CYM 5) as "we sit down at the table together" (CYM 10) after a day apart. The ideal for most families is to achieve value by attaining the superordinate goal of a happy family life around the dinner table and interactions with family and friends.

As evidenced in this consumer analysis, value for consumers does not emerge merely from activities rendered possible by ownership and use, as argued by Heinonen et al., (2010, 2013). It requires another precondition. Activities must promote individuals' higher goals: the outcomes of activities have to be meaningful to them to create value. Thus, the analyses following the goal hierarchy construct add a new dimension to consumer value creation. In this case, consumers strive for good food and proper meals to attain a healthy and pleasant life and a harmonious family atmosphere. By applying the goal hierarchy construct, new dimensions in value creation emerge, vertically by identifying superordinate value dimensions and horizontally by pinpointing the different subordinate goals (means) explaining how the focal goal (the core/nucleus of the goal concept) is attained.

\section{The firms' level}

Analysis of the transcribed interviews of firm representatives followed the same procedures as for consumers to identify emerging patterns of reactions (Glaser, 2011). The focal goals shed light on what is in the minds of retailers and suppliers in their interactions with consumers and with each other. To firms, the focal goal is a means of rapprochement to consumers' wants and needs, and they depict this strategy as consumer orientation. This concept is typically used both by scholars and practitioners (see Narver and Slater, 1990; Jaworsky and Kohli, 1993; Elg, 2007) but is interpreted in different ways (Ottesen and Grönhaug, 2004). However, a common denominator is the focus on consumer intelligence. Based on how firms in this study portray their consumer focus, we have conceptualized it as focalization of product/ assortment development.

The data helped to identify five primary strategies or means that firms essentially use to reach their focal goals. Three of them are at the subordinate level: "Product and assortment development," "Communicating favorable prices" and "Consumer communication and information." The means at the sub-subordinate level are "Acquiring consumer understanding" and "Retailer-supplier cooperation," where they serve as support to the subordinate goals (see Fig. 3).

Conceptualizing and structuring of firms' activities following the goal hierarchy approach result in the following model construction:

The subordinate goals highlight in detail how firms act to attain their focal goal.

\subsection{Product and assortment development}

Respondents from suppliers and retailers unanimously stated that a consumer-oriented strategy in support of consumers' value creation is a priority. In their own terms, they strive to be genuinely consumer oriented by placing consumers' wants and needs at the core of their operations and strategy. Eventually, this strategy generates increased sales and profitability, since "without [consumers'] acceptance of our products, our company has no raison d'être" (marketing manager, supplier). Indeed, product/assortment development is a central means for firms to contribute to consumer value creation, although they express their ambitions in different ways: "In our product development, we want to contribute to solving consumers' everyday household puzzle" (marketing manager, supplier); "Our new product should be of higher quality than any of our competitors. Well, we also charge higher prices" (marketing manager, supplier); "High quality, sound products and trustworthy alternatives are our guiding principles" (CEO, supplier); "The guidelines for our product development are first to confirm that new ideas are attractive to consumers and then to ensure that communication to consumers is straightforward and clear" (marketing manager, supplier). The retail unit has well-defined guidelines on how to serve consumers: "Provide pleasure of food by addressing all consumer senses and by providing inspiration. Concurrently, health has a strong impact" (marketing executive, retail unit). The retail unit places a strong emphasis on product/assortment development, as "a clear store design, a deliberate product display and a service-oriented staff" are "important means to support consumers in their shopping" (marketing executive, retail unit). They endeavor to meet the demands of modern consumers through research and innovation.

However, by limiting their value facilitation to the product and assortment area, firms utilize only a fraction of the tools at their disposal to create value. Integrating resources from different actors in the network would allow actualization of their value potential and would more closely meet consumers' focal goals. Some solutions in this direction are, however, appearing. One early example is Lina's "food bag," offering ingredients and recipes for families of different sizes and eating styles. The bags cover three to five meals per week and are delivered to homes. This shopping bag concept has now been adopted by all food chains in Sweden, offering pick-up at stores or home delivery. In addition, independent entrepreneurs are advancing the concept in different directions.

\subsection{Communicating favorable prices}

Pricing is a central issue in the food industry, and firms pursue the goal of delivering good prices or the best price in a variety of ways. Firms differentiate prices by categorizing their products as budget, standard and premium. Some retail chains operate their stores as exclusively low-cost outlets. Bonuses and special offers for the week are standard procedures. Cooperation between producers and retail chains consists largely of planning current and continuing promotion programs. In fact, firms devote most of their marketing energy to pricing strategies.

\subsection{Consumer communication and information}

For suppliers, the product and its packaging are the most important means of communicating with consumers. They also employ more traditional approaches, such as product demonstrations in stores, together with distributing flyers with recipes that enable consumers to sample the products and get inspiration for how they could be used. Television and the company's website are additional means for relaying product information to consumers. However, suppliers struggle to communicate to consumers what they stand for and how seriously they take product quality and consumer needs: "The difficulties are about how to communicate this information to consumers" (marketing manager, supplier). The primary challenge in the communication process is the fact that consumers may perceive the marketing channel as biased and untrustworthy: “...we wish we had a neutral channel for consumer communication through which we could present the serious manner in which we develop our products and how safe our products are" (CEO, supplier). Compared to suppliers, retailers have almost unlimited options for communicating with their customers. In fact, retailers are well aware of how their customers perceive value but do not always respond 


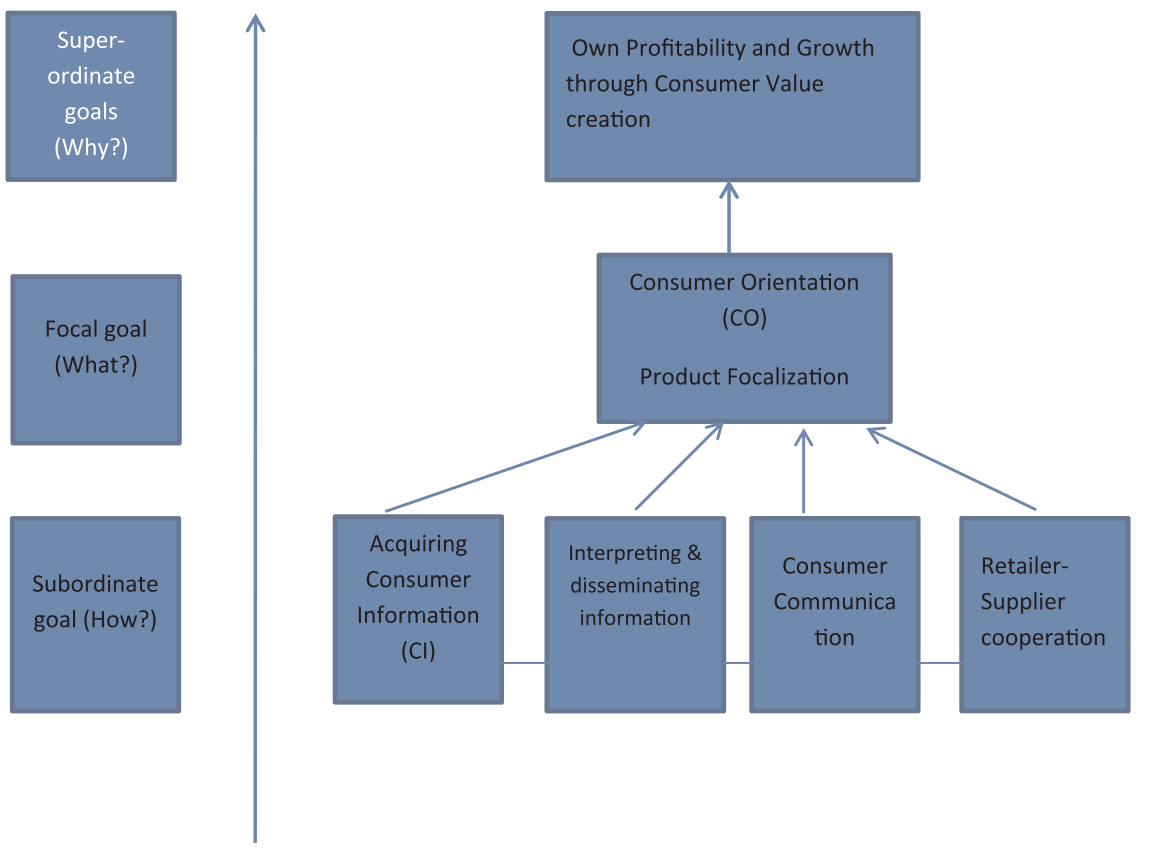

Fig. 3. Firms' goal hierarchy.

proactively: "we need to offer meal solutions and inspire [our customers] to buy whole meals (packages of products), not just the products displayed at the corners of the shelves" (assortment manager, retail unit).

\subsection{Acquiring consumer understanding}

To develop products and assortments that support optimal value for consumers at the subordinate level, firms need consumer insight as a sub-subordinate goal. Understanding consumers presupposes collecting, interpreting and disseminating consumer information. A key objective of firms is to understand in detail both the process by which their consumers ultimately come to purchase their products and the details of their goals.

The retail unit directs part of its consumer research toward monitoring its position in the minds of consumers. Customer satisfaction indices and attitude tracking (profile studies) serve to identify its strengths and weaknesses and to determine consumers' attitudes toward the company's product range, displays and promotion activities. Despite daily interactions and contact with consumers in stores to continuously derive vital consumer knowledge and information, retailers still "wish we had as deep an understanding of the consumers as the suppliers" (marketing executive, retail unit).

In fact, suppliers conduct extensive data gathering through consumer research. In reality, by gathering consumer information in an everyday context, suppliers ultimately emphasize the identification of product attributes meant to facilitate product development and brand penetration, to the detriment of a more holistic view (focal goals) of consumers' needs and wants. This limitation is attributed to the complexity of consumer behavior, which is seen as "complex actions difficult to understand and that will most likely fail to answer why and how consumers act as they do" ( manager of a firm's CI department). And yet, however fatalistic they may sound, firms are adamant that they must better understand the everyday lives of consumers and how consumers manage their food and meal arrangements. They are also self-critical in acknowledging that their methods of acquiring consumer insights are "insufficient and inadequate," (manager of a firm's CI department) expressing the need for additional ethnographic data for a more complete understanding of consumers. The need for better methods has support in both theory and practice literature (see e.g. Arken, 2002).

Thus, consumer understanding emerges as the most decisive subordinate goal that firms need to adopt in order to implement a consumer orientation (Kennedy et al., 2003). Understanding consumers requires valuable "consumer intelligence" (CI) that is often found with other actors within the network. To that end, "we try to keep a close dialogue with them [suppliers] to use their knowledge and the intelligence they have about consumers" to enhance understanding of consumers in order to "satisfy their needs for different product sizes, tastes, etc." (marketing manager, retailing). "To get to know what is important to the consumers" and to understand consumers are "the greatest challenges in our consumer relations" (CEO, supplier). Firms find it difficult to interpret and disseminate the data they receive in a useful way "and to present the information to other employees in the company in a way that is simple and easy to understand" (manager of a firm's CI department).

Firms also confess that their failure in disseminating consumer information is due to weaknesses in their organizational structure. No procedures exist to ensure that available information will reach all of the involved actors. Therefore, beyond the mere necessity to understand consumers, firms must "... present the information in a way that is easy to comprehend for the people in the organization and to make use of it," (manager of a firm's CI department), which is another challenge for firms in supporting consumer value creation. This confirms that firms' activities are somewhat disconnected from the information processes that are central to consumers in actualizing value.

\subsection{Retailer-supplier cooperation}

Firms palliate to this communication conundrum by coordinating retailers' and suppliers' consumer-oriented activities (Morgan and Hunt, 1994). In this study, firms maintain that better coordination of consumer-oriented activities has the potential to help them improve operational efficiency and consumer value creation. However, the data reveal no consensus between retailers and suppliers regarding how their activities, or facilitating factors, actually interact and how cooperation between them should function. The two groups further disagree about the reasons behind the difficulty in achieving coordination. Suppliers emphasize that downstream, retailers are primarily transaction-oriented, focusing on price, volume and profitability instead of addressing consumers' wants and needs. They stress that conversations with retailers at an earlier stage in the interaction process would facilitate mutual value creation, thereby enabling suppliers to better adapt their products to retailers' specifications and provide them with valuable product expertise before their encounter with customers. 
However, the concentration of power in the Swedish retail market and the fact that retailers' brands are private make extensive collaboration between suppliers and retailers difficult. Suppliers fear that if they are perceived as working creatively with a particular retail group, other retail groups may notice and react negatively, and "we could not [survive] if the dominant retailer would vanish" (sales manager, supplier).

On the other hand, retail units perceive their relationships with suppliers as "[...] generally uncomplicated" and "ruled by the performance of unproblematic negotiations and agreements," (marketing executive, retail unit) except when it comes to the product development process. Retailers indicate that product attributes and product development are not normally discussed with brand manufacturers because "[our] limited market share and small size prevent [us] from asking for specific or modified products, for fear of retaliation from the bigger retail unit" (marketing executive, retail unit). Overall, the data reveals that suppliers and retailers are pessimistic with regard to their ability to achieve a more active cooperation.

\section{Discussion}

In this paper we argue for an inductive/empirical approach to elaborate upon the value concept and unpack the process of its creation. By use of the goal hierarchy as our theoretical lens and to disclose how firm- and consumer-led activities produce consumer value, we addressed four questions. To the first question of "What represents consumer value in a given consumption situation?" we showed that by applying the goal hierarchy approach, consumer value emerges on different abstraction levels. The central value concept represented by the focal goal denotes what is important in a given consumption context. This value concept appears before the consumer has chosen and used the product or service. Consumers' value image is generated from previous experience and is created in the consumers' own space. We suggest that the focal goal represents the core value concept; i.e. what is genuinely important for the consumers. Value creation manifests itself once the focal goal is attained. Although attaining the focal goal parallels value-in-use, it is nevertheless more complex. In our case, the focal value (goal) is "good food" and presupposes attaining four value variables: healthy and nourishing food, product combinations, the best price and sensory and social pleasure. To illustrate the multidimensional value dimensions, we can project how consumers in other areas might think. For a furniture shopper, the focal value could be "a comfortably furnished cozy living room," while for an apparel shopper, "a smashing outfit for vacation in Paris." At this level, consumers create/identify value in their own space based on previous consumption experience within that area. These reflections forego the search for products and services that render value-in-use. There is, however, an additional value concept at the apex of the goal hierarchy that asks: "What are the reasons for striving to attain the focal value?" Following Bagozzi and Dholakia (1999), the answer is that activities have to be meaningful for the consumer. We therefore propose that a precondition for attaining genuine value is that the value experience is a significant component of the individual's private life, thereby providing a new dimension in consumer value creation at the top of the goal hierarchy. In our case, food realizes its value when it contributes to a healthy and happy family life. Thus, by identifying the superordinate goal- that consumption has to be meaningful for creating genuine value - the study extends the established value-in-use concept and thereby adds to the theory of consumer value creation.

To address the second question, "How do singular components of value contribute to value in specific consumption areas?" we explored consumers' conveyed means and preconditions for attaining the value dimension to identify attributes of products and services that create value for the consumer. In other words, the search is about identifying the means to acquire the focal value (goal). The goal hierarchy in Fig. 2 highlights the process of consumer value creation regarding food and meal arrangements. In the furniture case, the reported means could be a combination of products that are easy to clean and lift, are durable and save space, with a pleasing color palate and a good price. For the apparel shopper, the means could be a rich assortment of fashion, service/ advice, moderate prices, and clear information on materials and cleaning. The outcome of the search process is the acquisition and use of the chosen products and services. At this final step value-in-use is created. As we argue, the focal goal (value) provides information that is at least as important as value-in-use.

To answer the question "What are the contributions of the different actors in value creation?" we explored firms' consumer support activities following the goal hierarchy construct. Fig. 1, which is based on network theory (Sarker et al., 2006) decrees that the actors' activities should be coordinated for optimal consumer value creation. This means that firms have to support consumers' focal goals. In this case they relate to addressing holistic concerns regarding consumers' food and meal arrangements. Firms, however, perceive their focal goal as consumer orientation (which is in reality product focalization). This focal goal is supposed to facilitate profitability (superordinate goal). Without profitability, the activities are not meaningful for firms. However, firms' consumer-oriented activities and their focal goal are not fully in line with the consumers' focal goal. Firms only marginally address consumers' need for holistic food solution. Thus, firms are not attaining optimal profitability, and consumers do not attain optimal consumer value. As has been demonstrated, juxtaposing firms' and consumers' goal hierarchies may function as a checkpoint for firms to ascertain whether (i) their activities are in line with their focal goal, and (ii) whether their focal goal is in line with consumers' focal goal.

Analyzing the activities of both actors following the goal hierarchy construct clarifies the barriers to an optimal consumer value creation. In our food and meal case, firms' focal goals only partially match those of consumers. A study from the retail industry exhibits similar results (Bäckström and Johansson, 2006). The perceptions of retailers and consumers differ considerably as to what creates a pleasurable consumer experience (value) in in-store environments. Fig. 4 shows the shortcomings in firms' attempts to meet consumers' wants and needs and highlights several reasons behind such failure, as opposed to other models in the literature that merely provide information about what firms should do to create value for consumers (see Fig. 3). First of all, firms' consumer insight is limited and/or narrow, as stated by the firms themselves. This testimonial has support in extant literature (see, e.g., Grönroos and Voima, 2013). Firms also note that they lack efficient and easy-to-use consumer intelligence methods. This study proposes to close the loop between firms and consumers through consumer understanding that relies on the consumer goal hierarchy. The goal hierarchy approach creates an efficient tool for collecting and applying market intelligence (Sarker et al., 2006).

As consumers' focal goals tend to be multifaceted (Rintamäki et al.,

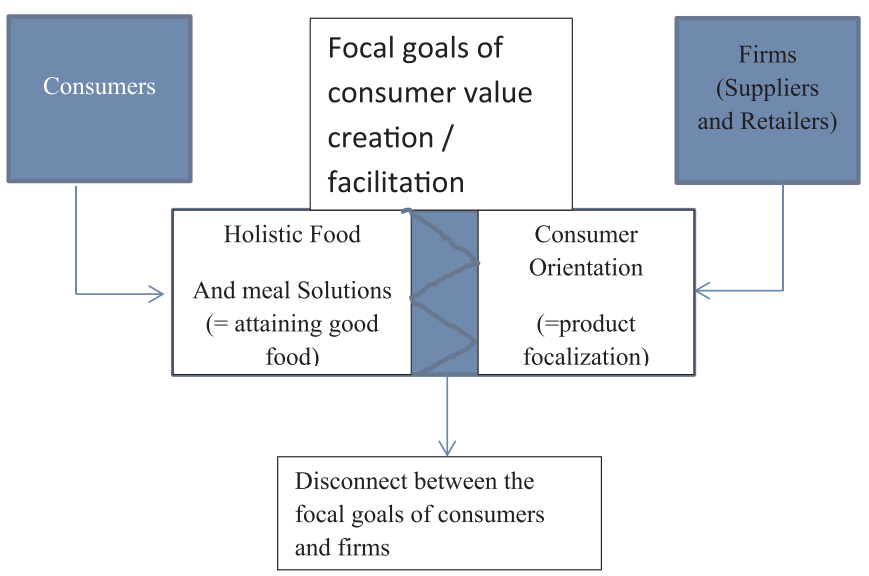

Fig. 4. Depicting the area of disconnect between consumers and suppliers. 
2007) it may be difficult for a single provider to match consumers' focal goals (Wikström and Normann, 1994; Normann and Ramirez, 1993). Alliances are needed. In this study, retailers and providers, for various reasons, find it difficult to cooperate in support of consumers' striving for holistic solutions. Thus, consumers have to resolve the problem on their own. This lacuna could be filled by a relieving and/or enabling strategy (Wikström and Normann, 1994; Normann and Ramirez, 1993). Relieving strategies are designed to remove the obstacles that prevent customers' value creation. Enabling strategies, on the other hand, provide consumers with the necessary tools and resources to attain their goals on their own in a more efficient way. Digital technology could be an enabling tool for consumers in their striving for holistic solutions. So far, Lina's "shopping bag" is one of relatively few examples of an enabling strategy in the food and meal area that has spread across the retail food sector. Consumers can order bags on the Internet containing menus and products for between two and five dinners for the week that are adapted to different family types. In the furnishing sector, IKEA provides a striking example of both relieving and enabling consumer value creation. Exhibits in IKEA stores demonstrate how to furnish housing units of different sizes for convenient and attractive living at a modest price. IKEA's catchword is "Providing comfortable housing for many people." IKEA not only sells furniture; it also provides what we characterize as holistic solutions to people's housing challenges. Additionally, the company solves customers' transportation problems by providing "flat packages," and by including tools and instructions, it allows customers to assemble the furniture themselves at home. Retail clothing firms increasingly offer personal shopping, particularly in department stores. The service includes advice on how to combine different apparels to create a useful wardrobe and advice on what to wear in different contexts. We argue that the retail sector has the greatest range of options to meet consumers' call for holistic solutions. They also have opportunities to build alliances with external actors to enter what Chan Kim and Mauborgne (2005) call "Blue Oceans," which are uncontested markets where there is a great disparity between quality and price and new offerings are introduced.

With regard to the final question, "How can consumer value be attained?" our network approach to the analysis of consumer value creation reveals that cooperation between the actors creates optimal value. As Fig. 1 shows, consumers are the primary actors because they focus exclusively on consumer value creation. The role of retailers and providers are important as well, but their consumer focus is shared by their superordinate goal: their own profitability. For them, consumer value facilitation is just one of several means of attaining profitability, although it is the decisive one. Following the network theory, we maintain that promoting cooperation between the actors fosters optimal value creation. In fact, we claim that consumer value-oriented interaction between the actors in the network creates the appropriate mechanisms for consumer value creation.

\section{Conclusion}

This study palliates to the lack of knowledge, as observed by Woodruff (1997) and Grönroos (2011), about processes involved in consumer value creation. It proposes that consumers create value through clear differential hierarchical goal settings (vertical) that include an identification of resources and consumers' own capacity before choosing and using products (breadth). Thus, within the Swedish food industry, consumers create value within the overarching goal setting and goal pursuit of holistic solutions by "acquiring healthy and nourishing food" and by pursuing efficient provisioning through appropriate product combinations at the best prices while ensuring pleasure of food. The paper extends contributions to the literature on the value-in-use concept through the goal hierarchy approach to an empirical study of the Swedish food and meal industry. The study identifies value as the focal goal; i.e., what constitutes value in a concrete and specific consumption situation and how it is generated through actions or strategies. Coupled with findings about consumers' feelings regarding their success in achieving the goal, this allows for a deeper appreciation of the characteristics of value beyond mere value-in-use. While the value-in-use paradigm starts from the use of a specific product/service, the goal hierarchy approach extends the dimensions of independent and social value creation of Grönroos and Voima (2013) by including:

(i) reflections about the antecedents of product use (the focal goal)

(ii) the starting point of value creation (selection and application of means);

(iii) the process involved (providing solutions); and ultimately

(iv) its contribution to life fulfillment.

The goal hierarchy concept sheds light on the process of value creation from different levels of abstractions; i.e., from the concrete subordinate level to the highly conceptual superordinate level through the instrumental focal level. For marketing purposes, firms benefit from being cognizant of these three levels so they can work towards helping consumers achieve the right level of goals. As such, the holistic value creation construct revealed in this study extends the value concept vertically through the degree of abstraction/concretization, and horizontally by the subordinate goals uncovering the different value dimensions inherent in the value reached.

The goal hierarchy approach offers to firms a new tool for consumer understanding that the business community has not extensively employed so far. The construct helps firms get away from an inward perspective by revealing and making consumer insights more accessible to firms, a necessary element in consumers' value creation processes. Similarly, the network approach demonstrates options for firms to provide consumers with holistic solutions through closer interactions between providers and retailers and eventually with other actors. This is a fourth space for consumer value creation that has received scant attention in marketing research.

Additionally, the study contributes by filling Grönroos and Voima's (2013) three spheres, where value is created, with empirical content. In concretizing the theoretical concepts, we conclude that the provider merely facilitates value creation in the provider sphere but seldom enters the joint sphere where both actors are supposed to interact. Thus, the joint sphere is essentially empty. Could it be that this is the case in most mass-produced consumer goods industries? Following Grönroos and Voima (2013, p 141), in the customer sphere, "[t]he customer is an independent value creator outside direct interaction." In the consumption context, however, the customer is always dependent on providers' resources in value creation, be it direct or indirect. As our data demonstrate, customers would benefit from more direct interaction in their value creation, which conceptually means an extension of the joint sphere. As a whole, the study indicates that greater interaction between the actors in a particular consumption area would enhance consumer value creation. This empirical evidence and conclusion have support from, for example, Wikström and Normann (1994) and Normann and Ramirez (1993), who argue that value creation benefits from involving more actors in the process. Similarly, Gummesson (2002) and Grönroos (2011) maintain that the network approach applied in pursuing value creation enables the exploration of such relationships between interdependent actors in the market. In this paper, the network approach has revealed that providers and retailers generally act independently of each other and thereby reduce the potential for consumer value creation.

\section{Managerial implications}

Our research provides relevant guidelines for managers to better understand their consumers and to bring their offerings in line with their corporate priorities. We encourage managers to broaden the view of what is important to consumers. The fact that providers focus on improving product quality and product development and retailers' 
extension of their assortment is not unimportant, but more is needed for optimal support of consumer value creation. The framework provided in this study can serve as a guide to managers in planning and analyzing their consumer-related behavior. Our study suggests that managers can more easily achieve their goals by identifying a broader spectrum of value dimensions than just product attributes and assortment development and moreover add value-supporting activities from other actors in the network. Finally, retailers would have rich possibilities to further consumer value creation by adding more enabling and relieving strategies in the form of services in the supply.

\section{Limitations and suggestions for future research}

The suggested network and goal hierarchy framework, based on an integration of extant literature with an analysis of data collected in the Swedish food industry, should be regarded as the first step in developing an extended framework for the established value-in-use concept and the process of value creation. The food context, upon which this study rests, represents a large part of households' budget. Nonetheless, it necessarily limits the relevance and application of the results to other industries and countries. This is particularly the case for validating the relevance of holistic solutions as a manifestation of consumer value as an extension of value-in-use. However, the fact that industrial markets are shifting from selling products and services to providing solutions suggests that the results of this study could be applicable in other retail sectors. Therefore, the application of the goal hierarchy approach highlighting in detail the process of consumer value creation, both theoretically and empirically, would benefit from further validation. The next step for theoretical development could include extensive empirical in-depth studies in other consumption areas, including the service industry. The findings from the combined goal hierarchy/network approach have indeed shed new light on the mechanisms of consumer value creation and have revealed new aspects within the till now dominant value-in-use concept. Finally, analyzing options in other consumption areas would provide useful insights about benefits from provider-retailer cooperation as identified, in this study, to be situated in a fourth space.

\section{Acknowledgement}

The authors would like to thank Maria Frostling Henningsson, Ludvig Thuresson and Martin Hedböm for collecting and structuring the data for the project. Annika Ravald has given valuable comments on earlier versions of the paper.

We also want to thank the reviewers for insightful and incisive comments that have allowed us to enhance the quality of this paper.

\section{Grants}

This study has been made possible by grants from Vinnova (Sweden's research and Innovation Agency, WWW.Vinnova.se) and HUI (Retail research agency, WWW.HUI.se); both institutions have provided economic resources for the project.

\section{References}

Achrol, R., 1997. Changes in the theory of interorganizational relations in marketing: toward a network paradigm. J. Acad. Mark. Sci. 25, 56-71.

Andreu, L., Sànchez, I., Mele, C., 2010. Value co-creation among retailers and consumers: New insights into the furniture market. J. Retail. Comsum. Serv. 17, 241-250.

Arken, A., 2002. The long road to consumer understanding. Mark. Res. 14 (2), 29-31.

Bäckström, K., Johansson, U., 2006. Creating and consuming experiences in retail store environments: comparing retail and consumer perspectives. J. Retail. Consum. Serv. 13, 417-430.

Bagozzi, R.P., Dholakia, U., 1999. Goal setting and goal striving in consumer behavior. J. Mark. 63, 19-32.

Boksberger, P., Melsen, L., 2011. Perceived value: a critical examination of definitions, concepts and measures for the service industry. J. Serv. Mark. 25, 229-240.
Boysen Anker, T., Sparks, L., Moutinho, L., Grönroos, C., 2015. Consumer dominant value creation: a theoretical response to the recent call for a consumer dominant logic for marketing. Eur. J. Mark. 49, 532-560.

Chan Kim, W., Mauborgne, 2005. Value innovation: a leap into the blue ocean. J. Bus. Strategy 26 (4), 22-28.

Elg, U., 2007. Market orientation processes in retailing: a cross national study. Eur. J. Mark. 1, 568-589.

Esper, L.T., Ellinger, A.E., Stank, T.P., Flint, D.J., Moon, M., 2010. Demand and supply integration: a conceptual framework of value creation through knowledge management. J. Acad. Mark. Sci. 38, 5-18.

Gallarza, M., Gil-Saura, I., Holbrook, M.B., 2011. The value of value: further excursions on the meaning and role of customer value. J. Consum. Behav. 10 (4), 179-191 (July/ August).

Giovanardi, M., Lucarelli, A., L'Espoir Decosta, P., 2014. Co-performing tourism places: The "Pink Night" festival. Annals Tour. Res. 44, 102-115.

Glaser, B., 2011. Getting Out of the Data: Grounded Theory Conceptualization. Sociology Press, Mill Valley, CA, USA.

Gordon, B.J., 1964. Aristotle and the development of value theory. Q. J. Econ. 78, $115-128$.

Grönroos, C., 2008. Service logic revisited: who creates value? And who co-creates? Eur. Bus. Rev. 20 (4), 298-314.

Grönroos, C., 2011. Value co-creation in a service logic - a critical analysis. Mark. Theory 11 (3), 279-301.

Grunert, K.G., Wills, J.M., 2007. A review of European research on consumer response to nutrition information on food labels. J. Public Heal. 13 (5), 385-399.

Grönroos, C., Voima, P., 2013. Critical service logic: making sense of value creation and co-creation. J. Acad. Mark. Sci. 41, 133-150.

Gummesson, E., 2002. Relationship marketing in the new economy. J. Relatsh. Mark. 1, 37-57.

Gutman, J., 1997. Means-end chains as goal hierarchies. Psychol. Mark. 6, 545-560.

Heinonen, K., Strandvik, T., Mickelsson, K.J., Edvardsson, B., Sundström, E., Andersson, P., 2010. A customer logic of service. J. Serv. Manag. 21 (4), 531-548.

Heinonen, K., Strandvik, T., Voima, P., 2013. Customer dominant value formation in service. Eur. Bus. Rev. 25 (2), 104-123.

Herzberg, F., Mausner, B., Snyderman, B.B. (Eds.), 1959. The Motivation to Work. John Wiley \& Sons, New York.

Holbrook, M.B., 2006. Consumption experience, customer value, and subjective personal introspection: an illustrative photographic essay. J. Bus. Res. 59, 714-725.

Hohl, K., Gaskell, G., 2008. European Public Perceptions of food risk: cross-national and methodological comparisons. Risk Analy. 28 (2), 311-324.

Ind, N., Coates, N., 2013. The meaning of co-creation. Eur. Bus. Rev. 25 (1), 86-95.

Jaworsky, B., Kohli, A., 1993. Market orientation. Antecedents and consequences. J. Mark. 57, 53-70.

Kennedy, K., Goolsby, J., Arnold, E., 2003. Implementing a customer orientation: extension of theory and application. J. Mark. 67, 67-83.

Lamont, W.D., 1955. The Value Judgment. University Press, Edinburgh.

Latour, B., 2005. Reassembling the Social: An introduction to Actor-Network-theory. Oxford University Press, Oxford.

Lusch, R.F., Vargo, S.F., Tanniru, M., 2010. Service, value networks and learning. J. Acad. Mark. Sci. 38, 19-31.

Lusch, R.F., Vargo, S.L., O'Brien, M., 2007. Competing through service: insights from service-dominant logic. J. Retail. 83 (1), 5-18.

Maslow, A.H., 1943. A theory of human motivation. Psychol. Rev. 50 (4), 370-396.

Mencarelli, R., Lombart, C., 2017. Influences of the perceived value on actual repurchasing behavior: empirical exploration in a retailing context. J. Retail. Consum. Serv. 38, 12-21.

Morgan, R.M., Hunt, S.D., 1994. The commitment-trust theory of relationship marketing. J. Mark. 58, 20-38.

Narver, J., Slater, S., 1990. The effects of market orientation on Business Profitability. J. Mark. 54, 20-35.

Normann, R., Ramirez, R., 1993. From value chain to value constellation. Harv. Bus. Rev. 65-77.

Ottesen, G.G., Grønhaug, K., 2004. Barriers to practical use of academic marketing knowledge. Mark. Intell. Plan. 22 (5), 520-530. http://dx.doi.org/10.1108/ 02634500410551905.

Payne, A.F., Storbacka, K., Frow, P., 2008. Managing the co-creation of value. J. Acad. Mark. Sci. 36 (1), 83-96.

Pieters, R., Baumgartner, H., Allen, D., 1995. A means-end chain approach to consumer goal structures. Int. J. Res. Mark. 12 (3) (227-24).

Prahalad, C.K., Ramaswamy, V., 2004. Co-creation of experiences: the next practice in value creation. J. Interact. Mark. 18 (3), 5-14.

Perry, C., 1998. Processes of a case study methodology for postgraduate research in marketing. Eur. J. Mark. 32 (No. 9/10) pp. 785-802.

Ravald, A., Grönroos, C., 1996. The value concept and relationship marketing. Eur. J. Mark. 2, 19-30.

Rintamäki, T., Kuusela, H., Mitronen, L., 2007. Identifying competitive customer value propositions in retailing. Manag. Serv. Qual.: Int. J. 17 (6), 621-634. http://dx.doi. org/10.1108/09604520710834975.

Sarker, S., Sarker, S., Sidorova, A., 2006. Understanding business process change failure: an actor-network perspective. J. Manag. Inf. Syst. 1, 51-86.

Sirdeshmukh, D., Singh, J., Sabel, D., 2002. Consumer trust, value and loyalty in relational exchanges. J. Mark. 66, 15-37.

Strauss, A.L., Corbin, J.M., 1998. Basics of qualitative research: Techniques and procedures for developing grounded theory, $2^{\text {nd }}$ ed. Sage Publications, Thousand Oaks, CA. Swedish Competition Authority, 2011. Report No. 211:3 (In Swedish).

Vargo, S., Lusch, R.F., 2004. Evolving to a new dominant logic for marketing. J. Mark. 68, 
$1-10$.

Vargo, S., Lusch, R.F., 2008. Service-dominant logic: continuing the evolution. J. Acad. Mark. Sci. 36, 1-10.

Vargo, S., Lusch, R.F., Muglia, P.P., Akaka, M.A., 2008. On value and value co-creation: a service systems and service logic perspective. Eur. Manag. J. 26 (3), 145-152.

Warde, A., 1997. Consumption, Food and Taste. . Sage, London.

Wikström, S., 1996. Value creation by company- consumer interaction. J. Mark. Manag. $12,359-374$.

Wikström, S., Normann, R., 1994. (In Swedish 1992), Knowledge and Value - A New Perspective on Corporate Transformation. Routledge, London.

Woodruff, R.B., 1997. Customer value: the next source for competitive advantage. J. Acad. Mark. Sci. 25 (2), 139-153.

Yin, R., 2003. Case Study Research: Design and Methods, 3rd ed. Sage Publishing, Thousand Oaks, CA.
Solveig Wikström is Professor of business strategy and consumption at the Stockholm School of Business, Stockholm University. She has worked as marketing manager and serves as a board member in several public consumer goods and retail companies. Her research has mainly focused on the relations between firms and consumers, striving to improve the understanding of consumers and consumption experiences, which provides management with invaluable strategic insights.

Patrick L'Espoir Decosta is a senior lecturer in the Research School of Management at the Australian National University, Canberra, Australia. His areas of research encompass tourism behavior and consumption, tourism history, strategic tourism marketing, destination branding, qualitative methods of research and tourism and hospitality Education. He heads courses in Marketing, Marketing Research and Advertising. 